University of Wollongong

Research Online

Australian Institute for Innovative Materials -

Papers

Australian Institute for Innovative Materials

$1-1-2020$

Synthesis of hierarchical $\mathrm{Sn} / \mathrm{SnO}$ nanosheets assembled by carbon-coated hollow nanospheres as anode materials for lithium/sodium ion batteries

Fengrong $\mathrm{He}$

Qi Xu

Baoping Zheng

Jun Zhang

Zhenguo Wu

See next page for additional authors

Follow this and additional works at: https://ro.uow.edu.au/aiimpapers

Part of the Engineering Commons, and the Physical Sciences and Mathematics Commons

Research Online is the open access institutional repository for the University of Wollongong. For further information contact the UOW Library: research-pubs@uow.edu.au 


\title{
Synthesis of hierarchical Sn/SnO nanosheets assembled by carbon-coated hollow nanospheres as anode materials for lithium/sodium ion batteries
}

\author{
Abstract \\ This journal is The Royal Society of Chemistry. Tin-based anode materials have aroused interest due to \\ their high capacities. Nevertheless, the volume expansion problem during lithium insertion/extraction \\ processes has severely hindered their practical application. In particular, nano-micro hierarchical structure \\ is attractive with the integrated advantages of nano-effect and high thermal stability of the \\ microstructure. Herein, hierarchical $\mathrm{Sn} / \mathrm{SnO}$ nanosheets assembled by carbon-coated hollow \\ nanospheres were successfully synthesized by a facile glucose-assisted hydrothermal method, in which \\ the glucose served as both morphology-control agent and carbon source. The hierarchical $\mathrm{Sn} / \mathrm{SnO}$ \\ nanosheets exhibit excellent electrochemical performances owing to the unique configuration and carbon \\ coating. Specifically, a reversible high capacity of $2072.2 \mathrm{~mA} \mathrm{~h} \mathrm{g-1}$ was observed at $100 \mathrm{~mA} \mathrm{~g}-1$. Further, \\ $964.1 \mathrm{~mA} \mathrm{~h} \mathrm{g-1}$ after 100 cycles at $100 \mathrm{~mA} \mathrm{g-1}$ and $820.4 \mathrm{~mA} \mathrm{~h} \mathrm{g-1}$ at $1000 \mathrm{~mA} \mathrm{g-1}$ after 300 cycles could \\ be obtained. Encouragingly, the $\mathrm{Sn} / \mathrm{SnO}$ also presents certain sodium ion storage properties. This facile \\ synthetic strategy may provide new insight into fabricating high-performance Sn-based anode materials \\ combining the advantages of both structure and carbon coating. \\ Disciplines \\ Engineering | Physical Sciences and Mathematics

\section{Publication Details} \\ He, F., Xu, Q., Zheng, B., Zhang, J., Wu, Z., Zhong, Y., Chen, Y., Xiang, W., Zhong, B. \& Guo, X. (2020). \\ Synthesis of hierarchical $\mathrm{Sn} / \mathrm{SnO}$ nanosheets assembled by carbon-coated hollow nanospheres as anode \\ materials for lithium/sodium ion batteries. RSC Advances, 10 (10), 6035-6042.
}

\section{Authors}

Fengrong He, Qi Xu, Baoping Zheng, Jun Zhang, Zhenguo Wu, Yanjun Zhong, Yanxiao Chen, Wei Xiang, Benhe Zhong, and Xiaodong Guo 


\section{RSC Advances}

Check for updates

Cite this: RSC Adv., 2020, 10, 6035

Accepted 14th January 2020

DOI: 10.1039/c9ra08897k

rsc.li/rsc-advances
Received 29th October 2019

\section{Synthesis of hierarchical Sn/SnO nanosheets assembled by carbon-coated hollow nanospheres as anode materials for lithium/sodium ion batteries}

\author{
Fengrong $\mathrm{He},{ }^{a} \mathrm{Qi} X{ }^{*}{ }^{* b}$ Baoping Zheng, ${ }^{a}$ Jun Zhang, ${ }^{\mathrm{c}}$ Zhenguo $\mathrm{Wu},{ }^{\mathrm{D}}{ }^{\mathrm{b}}$ \\ Yanjun Zhong, (DD ${ }^{\mathrm{b}}$ Yanxiao Chen, (D) ${ }^{\mathrm{b}}$ Wei Xiang, $^{\mathrm{d}}$ Benhe Zhong $^{\mathrm{b}}$ \\ and Xiaodong Guo (D) *be
}

\begin{abstract}
Tin-based anode materials have aroused interest due to their high capacities. Nevertheless, the volume expansion problem during lithium insertion/extraction processes has severely hindered their practical application. In particular, nano-micro hierarchical structure is attractive with the integrated advantages of nano-effect and high thermal stability of the microstructure. Herein, hierarchical $\mathrm{Sn} / \mathrm{SnO}$ nanosheets assembled by carbon-coated hollow nanospheres were successfully synthesized by a facile glucoseassisted hydrothermal method, in which the glucose served as both morphology-control agent and carbon source. The hierarchical $\mathrm{Sn} / \mathrm{SnO}$ nanosheets exhibit excellent electrochemical performances owing to the unique configuration and carbon coating. Specifically, a reversible high capacity of $2072.2 \mathrm{~mA} \mathrm{~h} \mathrm{~g}^{-1}$ was observed at $100 \mathrm{~mA} \mathrm{~g}^{-1}$. Further, $964.1 \mathrm{~mA} \mathrm{~h} \mathrm{~g}^{-1}$ after 100 cycles at $100 \mathrm{~mA} \mathrm{~g}^{-1}$ and $820.4 \mathrm{~mA} \mathrm{~h} \mathrm{~g}^{-1}$ at $1000 \mathrm{~mA} \mathrm{~g}^{-1}$ after 300 cycles could be obtained. Encouragingly, the $\mathrm{Sn} / \mathrm{SnO}$ also presents certain sodium ion storage properties. This facile synthetic strategy may provide new insight into fabricating high-performance $\mathrm{Sn}$-based anode materials combining the advantages of both structure and carbon coating.
\end{abstract}

\section{Introduction}

Currently, considerable attention has been paid to lithium ion batteries (LIBs) for their promising application in hybrid electric vehicles (HEVs), electric vehicles (EVs) and large-scale renewable energy storage systems owing to their high energy density, long life span and relatively low environmental impacts. ${ }^{1-4}$ Although graphite is extensively employed as an anode, its limited theoretical density $\left(372 \mathrm{~mA} \mathrm{~h} \mathrm{~g}^{-1}\right)$ prevents it from meeting the ever-increasing requirements for higher power and energy density. ${ }^{5}$ Thus, tremendous efforts have been devoted to develop new anodes with higher specific capacity and excellent cycle stability for next-generation LIBs. ${ }^{6-10} \mathrm{Among}$ them, tin-based anode materials have been regarded as potential candidates with high theoretical capacity (Sn: $994 \mathrm{~mA} \mathrm{~h} \mathrm{~g}^{-1}$; SnO: $875 \mathrm{~mA} \mathrm{~h} \mathrm{~g}{ }^{-1}$; $\mathrm{SnO}_{2}: 783 \mathrm{~mA} \mathrm{~h} \mathrm{~g}{ }^{-1}$ ), natural abundance

${ }^{a}$ Dong guan Hec Technology Research Corporation, Dongguan, Guangdong 523871, P. R. China

${ }^{b}$ School of Chemical Engineering, Sichuan University, Chengdu 610065, P. R. China. E-mail: xiaodong2009@scu.edu.cn

'Ruyuan Dongyangguang Magnetic Material Limited Company, Shaoguan, Guangdong 512710, P. R. China

${ }^{d}$ College of Materials and Chemistry \& Chemical Engineering, Chengdu University of Technology, Chengdu 610059, P. R. China

${ }^{e}$ Institute for Superconducting and Electronic Materials, University of Wollongong, Wollongong, NSW 2522, Australia and environmental benignity. ${ }^{11,12}$ Unfortunately, Sn-based anodes inevitably suffer from pulverization and aggregation problems caused by the large volume variation $(>300 \%)$ during lithiation-delithiation processes, which would lead to the loss of interparticle contact and consequently rapid capacity fading during cycling processes. ${ }^{13,14}$

Substantial significant research studies have been focused on overcoming these problems. One effective strategy is to design shorten the electron and ion diffusion lengths. A variety of novel nanostructures including nanowires, ${ }^{15,16}$ nanosheets, ${ }^{17,18}$ nanoboxes, ${ }^{19}$ nanotubes ${ }^{20,21}$ and hollow nanospheres ${ }^{22-24}$ have been explored. Particularly, hierarchically porous nanostructures such as hollow nanospheres have drawn extensive interest due to their peculiar hollow interior, which can provide large contact area and short diffusion path as well as sustain the huge volume change, thereby improving the cycling stability. For example, Gurunathan et $a .^{25}$ have synthesized hierarchically porous $\mathrm{SnO}_{2}$ hollow microspheres (HMS) by employing the resorcinol-formaldehyde (RF) gel method. An initial discharge capacity of $800 \mathrm{~mA} \mathrm{~h} \mathrm{~g}^{-1}$ and $79 \%$ capacity retention could be delivered at $1 \mathrm{C}$ rate after 100 cycles when using Na-alginate as binder. Another available method is to introduce a carbon layer, which can not only buffer the volume expansion but also improve the electrical conductivity. For instance, $\mathrm{Li}$ and co-workers ${ }^{26}$ have designed $\mathrm{SnO}_{2}$ nanospheres with oxygen vacancies encapsulated in the $\mathrm{N}$-doped graphene various nanostructures to alleviate the mechanical strain and 
hierarchical network by an electrostatic adsorption-induced selfassembled together with a thermal reduction process. The asprepared sample exhibits excellent lithium storage properties with a high reversible capacity of $912 \mathrm{~mA} \mathrm{~h} \mathrm{~g}^{-1}$ at the end of 200 cycles at $0.5 \mathrm{~A} \mathrm{~g}^{-1}$ and $652 \mathrm{~mA} \mathrm{~h} \mathrm{~g}^{-1}$ at the end of 200 cycles at $1 \mathrm{~A} \mathrm{~g}^{-1}$. However, the synthesis of hollow structures is generally complicated and difficult to realize the structure design and carbon coating in a one-step process. Therefore, it is highly desirable to develop more efficient methods to fabricate materials integrating the advantages of both structure and carbon coating.

Although LIBs have dominated the portable electronics market in the past two decades, the high cost and limited lithium reserves potentially hinder their large-scale application from a long-time prospective. ${ }^{27,28}$ In this context, sodium ion batteries (SIBs) have emerged as promising alternatives owing to the advantage of natural abundance, even distribution, and lower cost of Na resources. ${ }^{29,30}$ Despite the similarity between Liion and Na-ion intercalation chemistry, graphite, which is commercially applied as an anode material for LIBs, is not a suitable option for SIBs due to sodium's unique characteristics. ${ }^{31,32}$ According to some previous reports, Sn-based materials are considered to be prospective SIB anodes. ${ }^{33,34}$ Zhang and coworkers $^{35}$ have prepared SnO nanosheets with controlled number of atomic layers and lateral size. A high reversible capacity of $665 \mathrm{~mA} \mathrm{~h} \mathrm{~g}{ }^{-1}$ after 100 cycles at $0.1 \mathrm{~A} \mathrm{~g}^{-1}$ and $452 \mathrm{~mA} \mathrm{~h} \mathrm{~g}{ }^{-1}$ after 1000 cycles at a high current density of $1.0 \mathrm{~A} \mathrm{~g}^{-1}$ was delivered, with superior rate capability. Qin et al. ${ }^{36}$ obtained tetrahedral SnO microflowers by means of an ultrafast ionic liquid-assisted microwave method. The as-prepared $\mathrm{SnO}$ anode exhibits high average coulombic efficiency (CE) (98.5\% for 50 cycles at a specific current of $100 \mathrm{~mA} \mathrm{~g}^{-1}$ ) together with an unprecedented capacity contribution in the low potential region ( $5 \mathrm{mV}$ to $0.5 \mathrm{~V}$ vs. $\mathrm{Na} / \mathrm{Na}^{+}$).

In this work, integrating the two typical strategies mentioned above, we successfully designed a hierarchical structure of $\mathrm{Sn}$ / SnO nanosheets composed of carbon-coated hollow nanospheres by a facile glucose-assisted hydrothermal method. The as-prepared $\mathrm{Sn} / \mathrm{SnO}$ sample exhibits outstanding lithiumstorage properties due to the unique configuration and carbon coating layer. A high reversible capacity of 964.1 $\mathrm{mA} \mathrm{h} \mathrm{g}^{-1}$ after 100 cycles at $100 \mathrm{~mA} \mathrm{~g}^{-1}$ and $820.4 \mathrm{~mA} \mathrm{~h} \mathrm{~g}^{-1}$ at $1000 \mathrm{~mA} \mathrm{~g}^{-1}$ after 300 cycles could be obtained. Surprisingly, the as-prepared sample also presents certain sodium ion battery properties. It's expected that this facile synthetic strategy could open a new sight into fabricating high-performance anode materials combining the advantages of both structure and carbon coating.

\section{Experimental section}

\subsection{Synthesis of hierarchical $\mathrm{Sn} / \mathrm{SnO}$ nanosheets}

All chemicals were analytically pure and used directly without further purification. The hierarchical $\mathrm{Sn} / \mathrm{SnO}$ nanosheets were prepared via a simple glucose-assisted hydrothermal treatment of commercial Sn nanoparticles (Nanjing Emperor Nano Material Co., Ltd, Nanjing, China). In a typical procedure, $2 \mathrm{~g}$ Sn nanoparticles and $6 \mathrm{~g}$ glucose (Sinopharm Chemical Reagent
Co. Ltd, Shanghai, China) were mixed in $60 \mathrm{ml}$ deionized water under vigorous stirring. The resultant hybrid was transferred to an oven and then maintained at $180{ }^{\circ} \mathrm{C}$ for $4 \mathrm{~h}$. After cooled down to room temperature, the product was obtained by centrifugation, washed several times with water and ethanol, and then dried at $80{ }^{\circ} \mathrm{C}$ in a vacuum oven for $12 \mathrm{~h}$.

\subsection{Material characterization}

The crystalline phase was identified by powder X-ray diffraction (XRD, Philips X'pert Pro Super X-ray diffractometer, Cu K $\alpha$ radiation). The semi-quantitative XRD analysis is done by pattern simulation using Jade software. The morphology was investigated by field emission scanning electron microscopy (SEM, HITACHI S-4800) and transmission electron microscopy (TEM, JEM 2100). Nitrogen adsorption/desorption measurement was conducted on a Micromeritics Tristar 3000 system and the specific surface area was evaluated using the Brunauer-EmmettTeller (BET) method. X-ray photoelectron spectroscopy (XPS) experiments were performed on a PHI QUANTUM 2000 instrument to determine the chemical composition of the samples.

\subsection{Electrochemical measurements}

The electrodes were prepared by spread the slurry of $75 \mathrm{wt} \% \mathrm{Sn} /$ SnO active material, $15 \mathrm{wt} \%$ acetylene black and $10 \mathrm{wt} \%$ LA 132 (an acrylonitrile copolymer-based binder, Chengdu Indigo Power Source Co. Ltd.) onto copper foil current collectors, followed by drying at $80{ }^{\circ} \mathrm{C}$ overnight in a vacuum oven. The mass loading of the electrode is about $2.0 \mathrm{mg} \mathrm{cm}^{-2}$. CR2025-type coin cells were employed to test the electrochemical properties of the electrodes. For lithium half-cells, lithium foil was served as the counter electrode and a polypropylene (PP) film (Celgard 2400) as the separator. The electrolyte consists of $1 \mathrm{M} \mathrm{LiPF}_{6}$ and a mixture of ethylene carbonate (EC)/dimethyl carbonate (DMC)/diethyl carbonate (DEC) (volume ratio $1: 1: 1$ ) with $2 \mathrm{wt} \%$ vinylene carbonate (VC) as the additive (Tinci Materials Technology Co., Ltd, Guangzhou, China). The sodium half-cells were assembled in a similar way. Metallic sodium and glass fiber (GF/A, Whatman) were utilized as the counter electrode and the separator, respectively. The electrolyte is composed of $1 \mathrm{M} \mathrm{NaPF}_{6}$ and a mixture of EC/DEC (volume ratio $1: 1$ ) (Fosai New Materials Co., Ltd, Jiangsu, China). Galvanostatic charge-discharge tests were performed on a LAND-2001A battery test system (Land Electronic Co., Ltd, Wuhan, China). Cyclic voltammetry (CV) measurement was conducted on a CHI 660D electrochemical workstation ( $\mathrm{CH}$ Instruments Co., Ltd, Shanghai, China).

\section{Results and discussion}

The crystalline structure and phase composition of the asprepared sample were characterized by XRD pattern. As shown in Fig. 1a, the diffraction peaks can be indexed to tetragonal $\mathrm{SnO}$ with a space group of (129) $\mathrm{P} 4 / \mathrm{nmm}$ (JCPDS card no. 78-1913) and tetragonal Sn with the space group (141) $I 4_{1} /$ amd (JCPDS card no. 89-2958), indicating the presence of metallic Sn and SnO in the composite, while no peaks of other impurities were detected. In addition, the strong intensity and 
sharpness of the diffraction peaks manifest good crystallinity of the sample. By means of semi-quantitative analysis of the XRD pattern, the mass ratio of $\mathrm{SnO}$ and $\mathrm{Sn}$ is determined to be about $89: 11$, indicating the dominance of $\mathrm{SnO}$ in the composite. The morphology and structure of the as-prepared $\mathrm{Sn} / \mathrm{SnO}$ sample was investigated by SEM and TEM images. As depicted in Fig. 1b, the Sn/SnO composite consists of densely stacked nanosheets with a diameter of about 200 to $300 \mathrm{~nm}$. A higher magnification image of the nanosheets (Fig. 1c) clearly presents a hierarchical structure composed of intimately interconnected nanospheres. TEM images display more details about the nanospheres. As can be seen from Fig. 1d, the Sn/SnO nanospheres have a hollow structure, with a diameter of about
$30 \mathrm{~nm}$. Additionally, a carbon shell with about $2 \mathrm{~nm}$ thickness can also be observed coating on the surface of nanospheres. In the representative HRTEM image (Fig. 1e), distinct crystal lattice with interplanar spacing of $0.311 \mathrm{~nm}$ and $0.318 \mathrm{~nm}$ are detected, corresponding to the (200) plane of Sn and (101) plane of SnO, respectively, further demonstrating the coexist of metallic Sn and SnO in the composite. The selected area electron diffraction (SAED) pattern (Fig. 1f) indicates the polycrystalline nature of the $\mathrm{Sn} / \mathrm{SnO}$ sample. The several lattice fringes can be assigned to the (222) and (111) plane of SnO, and the (112) plane of Sn.

$\mathrm{N}_{2}$ adsorption-desorption measurement was employed to estimate the specific surface area and pore characteristics of the
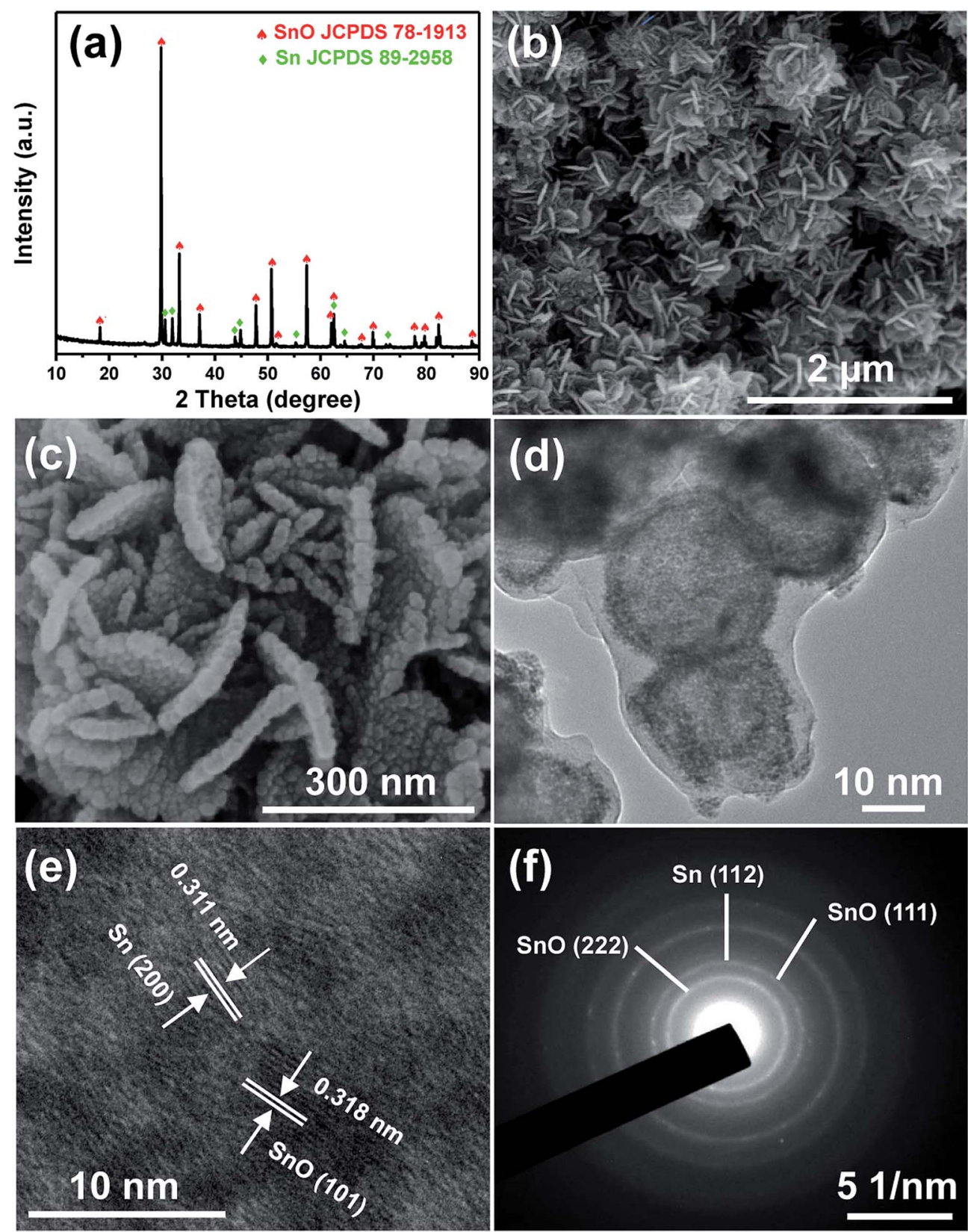

Fig. 1 (a) XRD pattern, (b and c) SEM images, (d) TEM image, (e) HRTEM image and (f) SAED pattern of the Sn/SnO sample. 


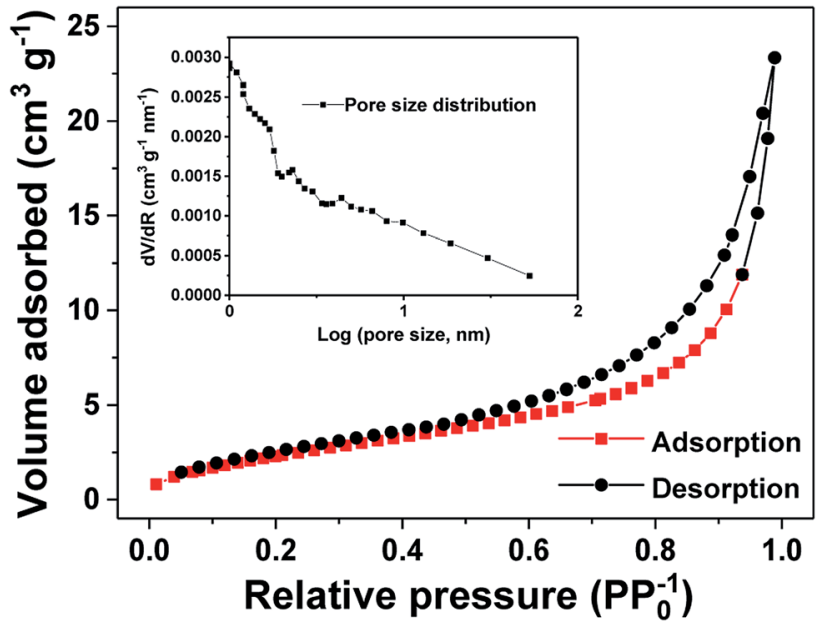

Fig. $2 \mathrm{~N}_{2}$ adsorption-desorption isotherms and corresponding pore size distribution curve (the inset) of the $\mathrm{Sn} / \mathrm{SnO}$ sample.

as-prepared $\mathrm{Sn} / \mathrm{SnO}$ sample. As revealed in Fig. 2, the $\mathrm{N}_{2}$ adsorption-desorption isotherm of the $\mathrm{Sn} / \mathrm{SnO}$ nanosheets appears as a type-IV curve with an evident type H3 hysteresis loop, suggesting the formation of mesoporous structure. On the basis of the Brunauer-Emmett-Teller (BET) method, the asprepared $\mathrm{Sn} / \mathrm{SnO}$ sample delivers a specific surface area of
$9.25 \mathrm{~m}^{2} \mathrm{~g}^{-1}$. The mean pore size and cumulative pore volume of the sample are about $7.18 \mathrm{~nm}$ and $0.035 \mathrm{~nm}$, respectively, as calculated from the pore size distribution curve (the inset of Fig. 2) by Barrett-Joyner-Halendar (BJH) method. Such porous structure with internal void can not only provide large contact area for electrode and electrolyte but also accommodate the volume change of $\mathrm{Sn} / \mathrm{SnO}$ nanosheet and facilitate the electrons and ions diffusion..$^{24,37}$

XPS spectra were applied to study the chemical state on the surface of the as-prepared sample. The high-resolution spectrum of C $1 \mathrm{~s}$ is depicted in Fig. 3a, which can be fitted into three peaks centered at 285.1, 286.7 and $288.4 \mathrm{eV}$, corresponding to $\mathrm{C}-\mathrm{C}, \mathrm{C}-\mathrm{O}$ and $\mathrm{C}=\mathrm{O}$ groups ${ }^{38}$ respectively. Fig. $3 \mathrm{~b}$ displays the typical high-resolution spectrum of $\mathrm{O} 1 \mathrm{~s}$, there are four peaks located at 531.5, 531.9, 532.6 and $533.5 \mathrm{eV}$, which are assigned to $\mathrm{O}_{2}, \mathrm{Sn}-\mathrm{O}, \mathrm{H}_{2} \mathrm{O}$ and $\mathrm{C}-\mathrm{O}$, separately. ${ }^{39}$ The Sn $3 \mathrm{~d}$ spectrum (Fig. 3c) shows two peaks appearing at $487.6 \mathrm{eV}\left(\mathrm{Sn} 3 \mathrm{~d}_{5 / 2}\right)$ and

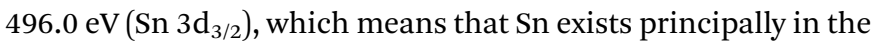
form of tin oxide..$^{40,41}$

The electrochemical performances of the $\mathrm{Sn} / \mathrm{SnO}$ sample as anode material for LIBs are investigated. Fig. 4a shows the CV curves of the $\mathrm{Sn} / \mathrm{SnO}$ sample in the potential window of $0-3.0 \mathrm{~V}$ (vs. $\mathrm{Li}^{2} \mathrm{Li}^{+}$) at a scanning rate of $0.1 \mathrm{mV} \mathrm{s}^{-1}$ for the first three cycles. An irreversible reduction peak at $0.9 \mathrm{~V}$ can be observed during the first cathodic sweep, which is associated with the
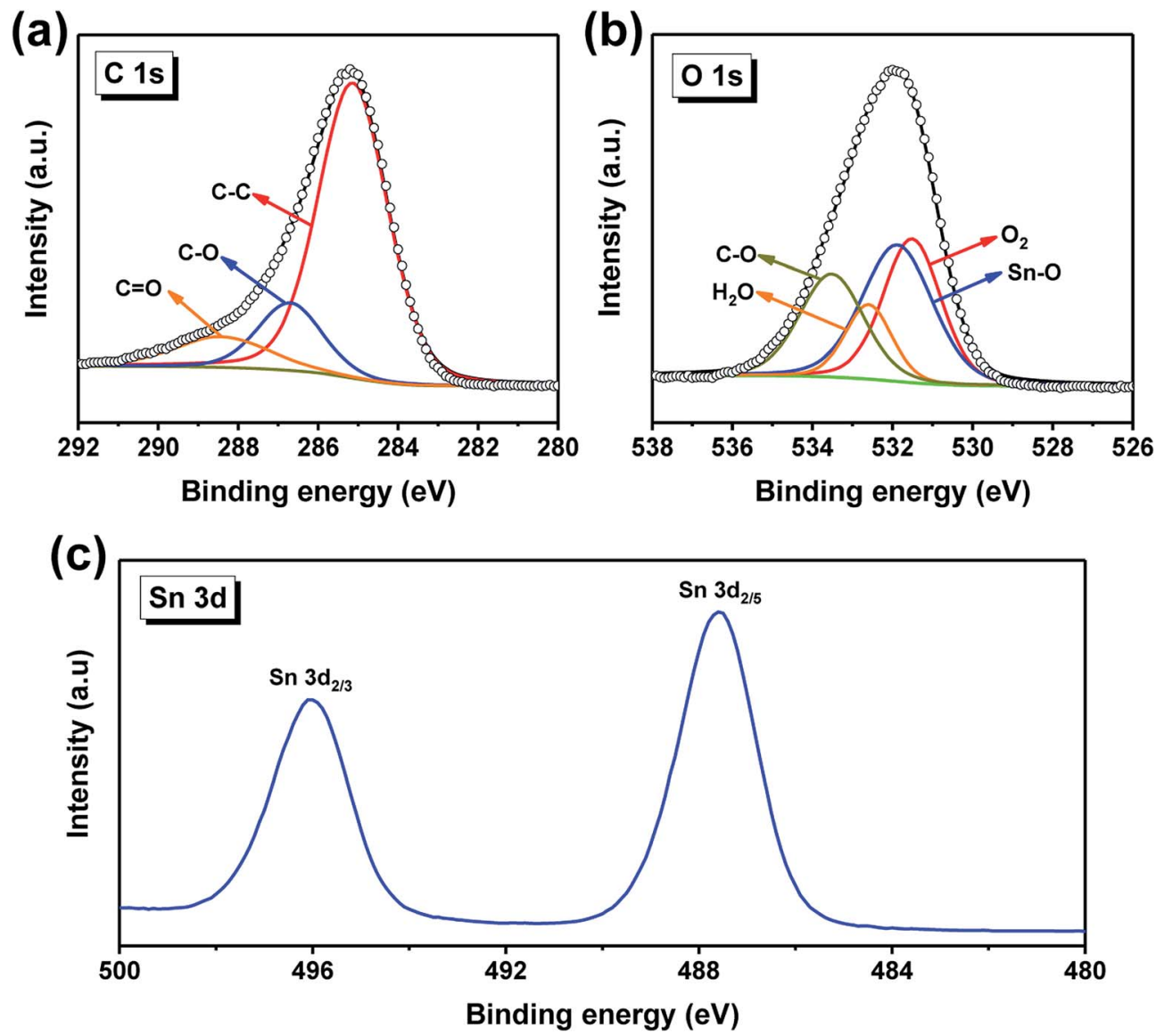

Fig. 3 XPS spectra of the Sn/SnO sample: (a) C 1s, (b) O 1s, (c) Sn 3d. 
reduction of $\mathrm{SnO}$ to metallic $\mathrm{Sn}$ and the formation of a solid electrolyte interface (SEI) layer on the electrode surface. ${ }^{42,43}$ The pronounced cathodic peak at the voltage close to $0.0 \mathrm{~V}$ can be ascribed to the alloying reaction of metallic Sn with lithium to form $\mathrm{Li}_{x} \mathrm{Sn}$. In the following anodic scan, a strong peak at $0.6 \mathrm{~V}$ and a broad peak at $1.27 \mathrm{~V}$ can be detected, corresponding to the dealloying reaction of $\mathrm{Li}_{x} \mathrm{Sn}$ and partial reversible formation of SnO, respectively, consistent with the Sn-based anodes reported previously. ${ }^{\mathbf{4 4 , 4 5}}$ Besides, the CV curves almost overlap in the subsequent cycles, indicating the formation of stable SEI film and good reversibility of the electrochemical reactions in the electrode.

Fig. $4 \mathrm{~b}$ shows the galvanostatic charge-discharge profiles of the $\mathrm{Sn} / \mathrm{SnO}$ nanosheets electrode for the first three cycles at a current density of $100 \mathrm{~mA} \mathrm{~g}^{-1}$ in a voltage window of $0.01-3 \mathrm{~V}$ (vs. $\mathrm{Li}^{+} / \mathrm{Li}$ ). The initial charge and discharge capacities are 1137.2 $\mathrm{mA} \mathrm{h} \mathrm{g}^{-1}$ and $2072.2 \mathrm{~mA} \mathrm{~h} \mathrm{~g}^{-1}$, corresponding to an initial coulombic efficiency (ICE) of 54.9\%. Note that the specific capacity was calculated on the basis of the total mass of the $\mathrm{Sn} / \mathrm{SnO}$ composite, including the negligible capacity supported by carbon. The large initial irreversible capacity loss (45.1\%) could be attributed to the formation of SEI layer on the electrode surface and the decomposition of the electrolyte. ${ }^{\mathbf{1 1 , 2 6}}$ After the first cycle, the CE climbs to $91.6 \%$ and $93.6 \%$ in the $2^{\text {nd }}$ and $3^{\text {rd }}$ cycles, respectively, indicating the formation of a stable SEI film.

The cycling performance of the as-prepared $\mathrm{Sn} / \mathrm{SnO}$ sample at a current density of 100 and $1000 \mathrm{~mA} \mathrm{~g}^{-1}$ are presented in

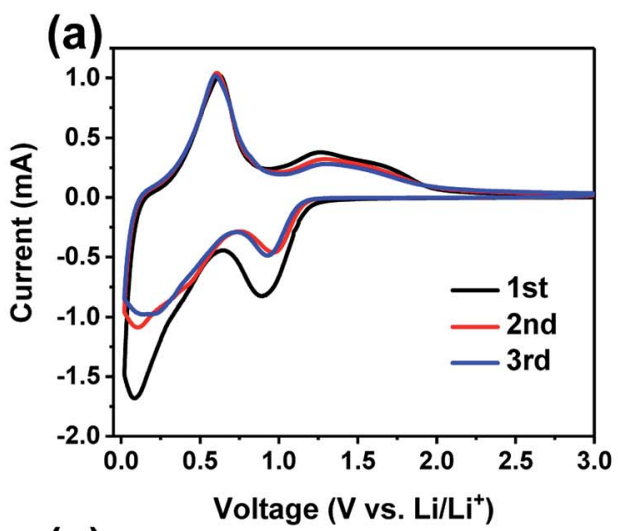

(b)
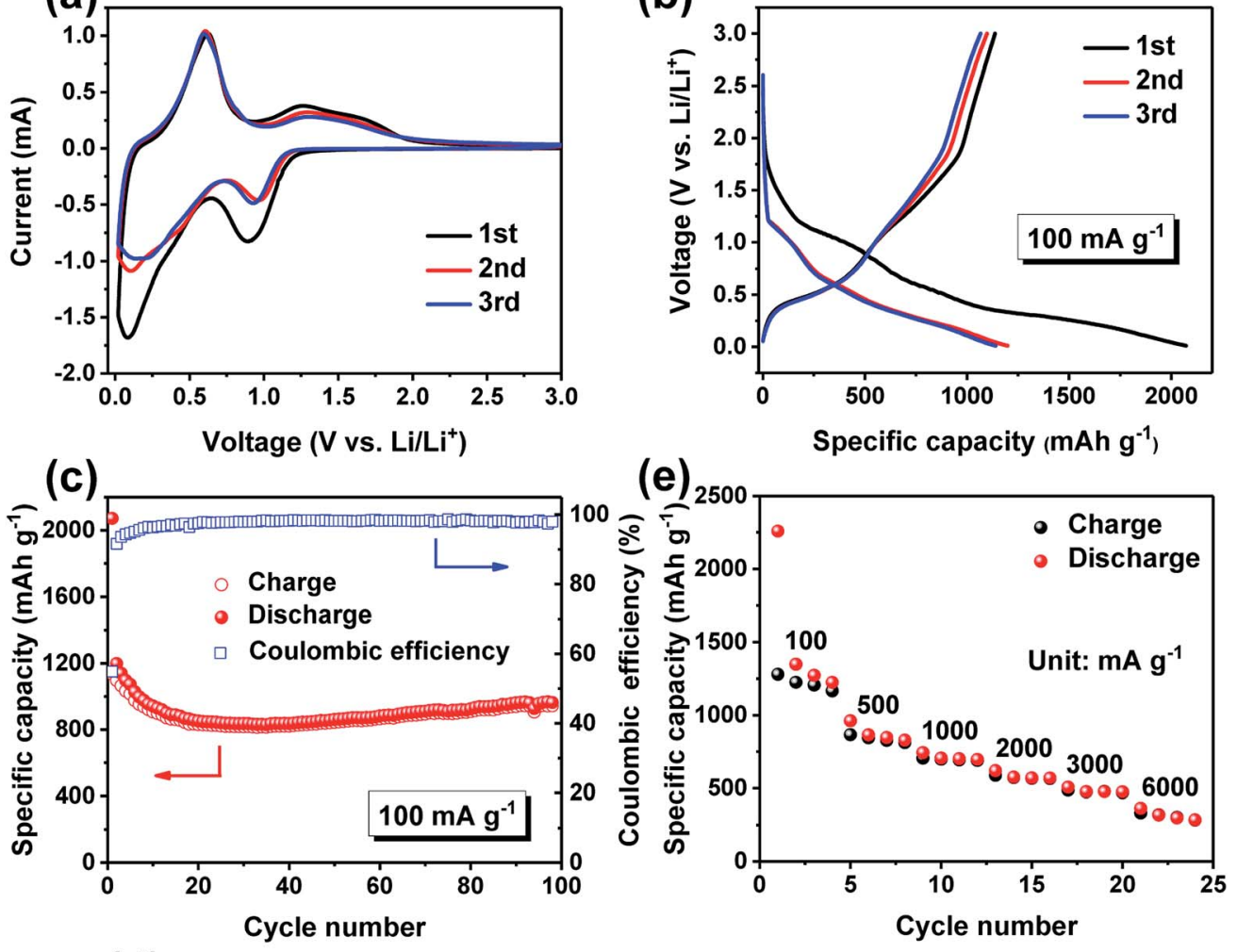

(d)

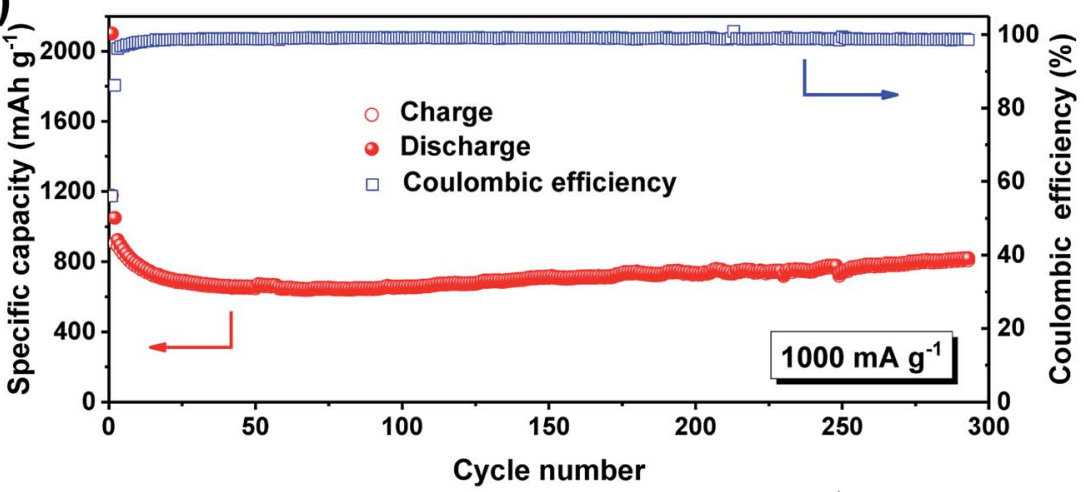

Fig. 4 (a) CV curves of the first three cycles at $0.1 \mathrm{mV} \mathrm{s}^{-1}$, (b) galvanostatic charge-discharge curves for the first three cycles at $100 \mathrm{~mA} \mathrm{~g}{ }^{-1}$, (c and d) cycling performances at 100 and $1000 \mathrm{~mA} \mathrm{~g}^{-1}$, (e) rate performances of the $\mathrm{Sn} / \mathrm{SnO}$ sample. 


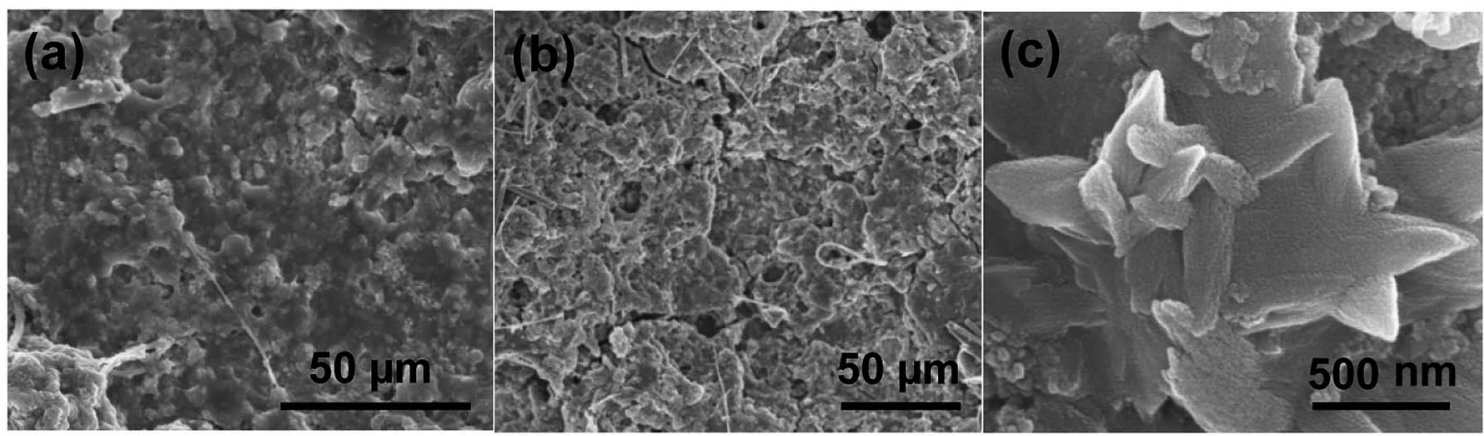

Fig. 5 SEM images of the Sn/SnO electrode (a) before cycling and ( $b$ and c) after 100 cycles at a current density of $100 \mathrm{~mA} \mathrm{~g}$.

Fig. 4c and d, respectively. As can be seen, the $\mathrm{Sn} / \mathrm{SnO}$ electrode delivers a reversible discharge capacity as high as 964.1 $\mathrm{mA} \mathrm{h} \mathrm{g}^{-1}$ after 100 cycles at $100 \mathrm{~mA} \mathrm{~g}^{-1}$ (Fig. 4c). Furthermore, after the first few cycles, the CE quickly increases and stabilizes at around $98 \%$ for the subsequent cycles, demonstrating the superior reversibility and cycling stability. When the current density increases to $1000 \mathrm{~mA} \mathrm{~g}^{-1}$, a discharge capacity of $820.4 \mathrm{~mA} \mathrm{~h} \mathrm{~g}^{-1}$ can still be obtained after 300 cycles, which is around $89 \%$ retention of the discharge capacity in the second cycle, revealing the excellent stability of the $\mathrm{Sn} / \mathrm{SnO}$ electrode (Fig. 4d). Interestingly, the capacity fluctuation phenomenon can be obviously observed during the cycling test, which has already been reported for many metal oxide anodes. ${ }^{11,46-48}$ This phenomenon may be mainly ascribed to the reversible formation/decomposition of an organic polymeric gel-like film on the electrode surface derived from the electrolyte decomposition, which could provide excess lithium ions storage sites. Fig. 4e depicts the rate capability of the $\mathrm{Sn} / \mathrm{SnO}$ nanosheets at different current densities ranging from 100 to $6000 \mathrm{~mA} \mathrm{~g}^{-1}$. It can be seen that the $\mathrm{Sn} / \mathrm{SnO}$ nanosheets electrode exhibits outstanding rate capability with reversible discharge capacity of 1349.2, 961.8, 743.9, 620.0, 507.1 and $363.7 \mathrm{~mA} \mathrm{~h} \mathrm{~g}^{-1}$ at a current density of 100, 500, 1000, 2000, 3000 and $6000 \mathrm{~mA} \mathrm{~g}^{-1}$, respectively.

The morphology changes of the electrode before cycling and after 100 cycles at $100 \mathrm{~mA} \mathrm{~g}^{-1}$ are presented in Fig. 5 . It can be
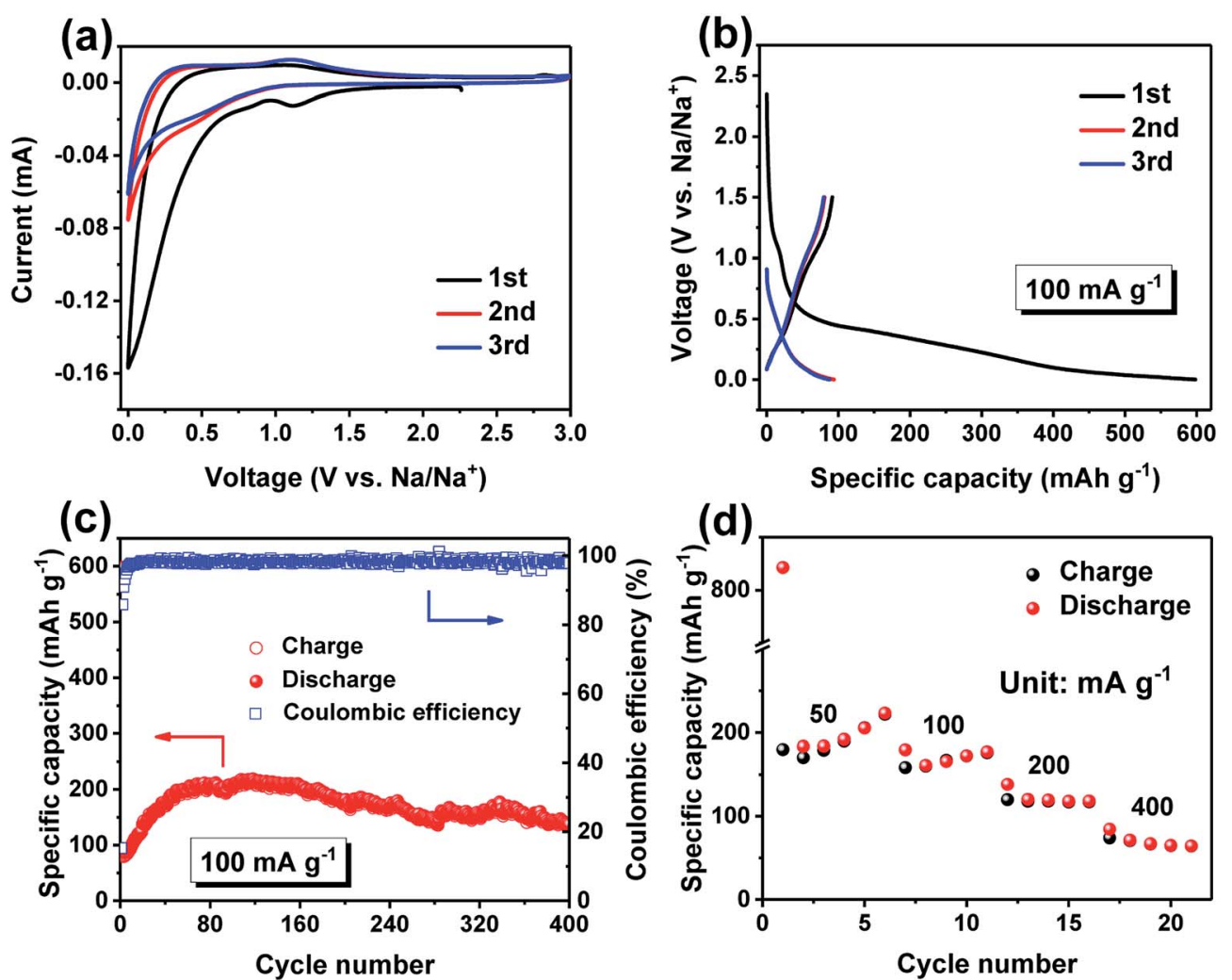

Fig. 6 (a) CV curves of the first three cycles at $0.1 \mathrm{mV} \mathrm{s}^{-1}$, (b) galvanostatic charge-discharge curves for the first three cycles at $100 \mathrm{~mA} \mathrm{~g}^{-1}$, (c) cycling performance at $100 \mathrm{~mA} \mathrm{~g}^{-1}$, (d) rate performances of the $\mathrm{Sn} / \mathrm{SnO}$ sample. 
seen that the active material still remains homogenously distributed on the current collector with only some cracks appeared (Fig. 5a and b). Although the hollow spheres are hard to be observed, the $\mathrm{Sn} / \mathrm{SnO}$ sample still preserves the sheet-like structure after long-time cycling (Fig. 5c).

The superior electrochemical performances of the $\mathrm{Sn} / \mathrm{SnO}$ nanosheets can be attributed to the following factors. First, the peculiar hierarchical structure of nanosheets composed of hollow nanospheres can provide more lithium storage sites and shorter lithium electrons and ions transport length. Second, the hierarchical structure could help relieve the volume change. Third, the carbon layer leads to enhanced electrical conductivity and better structure stability.

The sodium storage properties of $\mathrm{Sn} / \mathrm{SnO}$ anode were also investigated. Fig. 6a shows the $\mathrm{CV}$ curves of the $\mathrm{Sn} / \mathrm{SnO}$ electrode for the first three cycles at a scan rate of $0.1 \mathrm{mV} \mathrm{s}^{-1}$ between 0.0 and $3.0 \mathrm{~V}$. During the first cathodic scan, an irreversible peak at $1.1 \mathrm{~V}$ appeared, corresponding to the insertion of $\mathrm{Na}^{+}$into SnO and the formation of SEI film. The weak oxidation peaks in the charge process can be assigned to the reversible dealloying of $\mathrm{Na}_{x} \mathrm{Sn}^{.49-51}$ From the second cycle, all the redox peaks have few changes, implying the high electrochemical reversibility of the $\mathrm{Sn} / \mathrm{SnO}$ electrode. The representative charge-discharge curves for the initial three cycles of the $\mathrm{Sn} / \mathrm{SnO}$ sample at $100 \mathrm{~mA} \mathrm{~g}^{-1}$ are depicted in Fig. $6 \mathrm{~b}$. The initial charge and discharge capacity are 246.9 and $831.1 \mathrm{~mA} \mathrm{~h} \mathrm{~g}^{-1}$, respectively, corresponding to an ICE of $29.7 \%$. The irreversible capacity loss could also be ascribed to the irreversible electrolyte decomposition and formation of SEI on the surface of electrode. ${ }^{35,36}$ In the subsequent second and third cycles, the CE quickly increases to $97.5 \%$ and $92.2 \%$, respectively. The corresponding cycling performance is presented in Fig. 6c. As can be seen, a reversible discharge capacity of $137.0 \mathrm{~mA} \mathrm{~h} \mathrm{~g}{ }^{-1}$ could be delivered after 400 cycles. Specifically, after an evident increase for about 120 cycles, the specific capacity decreases slowly during the following cycles, indicating the material underwent an activated process. Such capacity increase has also been reported by Lu et al. ${ }^{52}$ Fig. $6 \mathrm{~d}$ illustrates the rate performances of the $\mathrm{Sn} / \mathrm{SnO}$ electrode at different current densities from 50 to $400 \mathrm{~mA} \mathrm{~g}^{-1}$. As can be seen, the electrode delivers a discharge capacity of 223.1, 179.6, 138.2 and $84.4 \mathrm{~mA} \mathrm{~h} \mathrm{~g}^{-1}$ at 50,100, 200 and $400 \mathrm{~mA} \mathrm{~g}{ }^{-1}$, respectively. These results demonstrate the inspiring electrochemical performances of the $\mathrm{Sn} / \mathrm{SnO}$ sample in SIBs.

\section{Conclusions}

In summary, we have successfully developed a facile hydrothermal method to synthesize hierarchical $\mathrm{Sn} / \mathrm{SnO}$ nanosheets assembled by carbon-coated hollow nanospheres. When evaluated as an anode material for LIBs, the $\mathrm{Sn} / \mathrm{SnO}$ sample exhibits excellent electrochemical properties. Specifically, a high reversible capacity of $2072.2 \mathrm{~mA} \mathrm{~h} \mathrm{~g}{ }^{-1}$ was observed at $100 \mathrm{~mA} \mathrm{~g}^{-1}$ with $964.1 \mathrm{~mA} \mathrm{~h} \mathrm{~g}^{-1}$ retained after 100 cycles. Moreover, $820.4 \mathrm{~mA} \mathrm{~h} \mathrm{~g}^{-1}$ can be maintained during a longterm cycling at $1000 \mathrm{~mA} \mathrm{~g}^{-1}$ after 300 cycles along with a remarkable rate capability of $363.7 \mathrm{~mA} \mathrm{~h} \mathrm{~g}^{-1}$ at $6000 \mathrm{~mA} \mathrm{~g}^{-1}$.
Furthermore, the $\mathrm{Sn} / \mathrm{SnO}$ sample also presents attractive sodium ion storage properties. Such superior electrochemical properties could be attributed to the unique architecture. On one hand, the peculiar hierarchical structure can not only provide more lithium storage sites, shorter lithium electrons and ions transport length but also help alleviate the volume variation as well as facilitate the electrolyte penetration. On the other hand, the carbon layer leads to enhanced electrical conductivity and better structure stability.

\section{Conflicts of interest}

There are no conflicts of interest to declare.

\section{Acknowledgements}

This work was supported by the National Natural Science Foundation of China (Grant No. 21878195, 21805198, 21805018), Distinguished Young Scholars of Sichuan University (2017SCU04A08) and Huohua Ku Project of Sichuan University (2018SCUH0094). Research Foundation for the Postdoctoral Program of Sichuan University (No. 2017SCU12018 and 2018SCU12045). Research Foundation for the Sichuan University and Zigong City Joint Research Project (2018CDZG-16). Thanks Dr Zhuo Zheng and for the help of data analysis.

\section{References}

1 N. Nitta, F. X. Wu, J. T. Lee and G. Yushin, Mater. Today, 2015, 18, 252-264.

2 J. B. Goodenough and K. S. Park, J. Am. Chem. Soc., 2013, 135, 1167-1176.

3 B. Scrosati, J. Hassoun and Y. K. Sun, Energy Environ. Sci., 2011, 4, 3287-3295.

4 J. M. Tarascon and M. Armand, Nature, 2001, 414, 359-367. 5 M. Winter, J. O. Besenhard, M. E. Spahr and P. Novák, $A d v$. Mater., 2010, 10, 725-763.

6 L. L. Wang, Q. F. Zhang, J. Y. Zhu, X. D. Duan, Z. Xu, Y. T. Liu, H. G. Yang and B. A. Lu, Energy Storage Mater., 2019, 16, 3745.

7 T. Chen, Z. G. Wu, W. Xiang, E. H. Wang, T. R. Chen, X. D. Guo, Y. X. Chen and B. H. Zhong, Electrochim. Acta, 2017, 246, 931-940.

8 L. Yu, H. B. Wu and X. W. Lou, Adv. Mater., 2013, 25, 22962300.

9 Z. G. Wu, Y. J. Zhong, J. Liu, J. H. Wu, X. D. Guo, B. H. Zhong and Z. Zhang, J. Mater. Chem. A, 2015, 3, 10092-10099.

10 Z. S. Wu, W. C. Ren, L. Wen, L. B. Gao, J. P. Zhao, Z. P. Chen, G. M. Zhou, F. Li and H. M. Cheng, ACS Nano, 2010, 4, 31873194.

11 C. Zhu, D. Wei, Y. Wu, Z. Zhang, G. Zhang, J. Duan, L. Li, H. Zhu, Z. Zhu and Z. Chen, J. Alloys Compd., 2019, 778, 731-740.

12 M. Sahoo and S. Ramaprabhu, Carbon, 2018, 127, 627-635.

13 Y. Zhao, X. F. Li, B. Yan, D. B. Xiong, D. J. Li, S. Lawes and X. L. Sun, Adv. Energy Mater., 2016, 6, 19. 
14 D. Saikia, J. R. Deka, C. J. Chou, H. M. Kao and Y. C. Yang, J. Alloys Compd., 2019, 791, 892-904.

15 C. Guan, X. Wang, Q. Zhang, Z. Fan, H. Zhang and H. J. Fan, Nano Lett., 2014, 14, 4852-4858.

16 W. Ren, C. Wang, L. Lu, D. Li, C. Cheng and J. Liu, J. Mater. Chem. A, 2013, 1, 13433-13438.

17 Y. Q. Zhu, H. Z. Guo, H. Z. Zhai and C. B. Cao, ACS Appl. Mater. Interfaces, 2015, 7, 2745-2753.

18 W. Su, Y. Liang and Y. Tang, J. Alloys Compd., 2019, 801, 402408.

19 Z. Wang, D. Luan, F. Y. Boey and X. W. Lou, J. Am. Chem. Soc., 2011, 133, 4738.

20 C. H. Han, B. X. Zhang, K. N. Zhao, J. S. Meng, Q. He, P. He, W. Yang, Q. Li and L. Q. Mai, Chem. Commun., 2017, 53, 9542-9545.

21 Y. Wang, H. C. Zeng and J. Y. Lee, Adv. Mater., 2006, 18, 645649.

22 H. Woo, S. Wi, J. Kim, J. Kim, S. Lee, T. Hwang, J. Kang, J. Kim, K. Park and B. Gil, Carbon, 2018, 129, 342-348.

23 W. S. Kim, Y. Hwa, J. H. Jeun, H. J. Sohn and S. H. Hong, J. Power Sources, 2013, 225, 108-112.

24 B. K. Cao, Z. Q. Liu, C. Y. Xu, J. T. Huang, H. T. Fang and Y. Chen, J. Power Sources, 2019, 414, 233-241.

25 P. Gurunathan, P. M. Ette and K. Ramesha, ACS Appl. Mater. Interfaces, 2014, 6, 16556-16564.

26 N. T. Wu, W. Z. Du, X. Gao, L. Zhao, G. L. Liu, X. M. Liu, H. Wu and Y. B. He, Nanoscale, 2018, 10, 11460-11466.

27 S. Y. Hong, Y. Kim, Y. Park, A. Choi, N.-S. Choi and K. T. Lee, Energy Environ. Sci., 2013, 6, 2067-2081.

28 P. K. Nayak, L. Yang, W. Brehm and P. Adelhelm, Angew. Chem., Int. Ed., 2018, 57, 102-120.

29 J. Y. Hwang, S. T. Myung and Y. K. Sun, Chem. Soc. Rev., 2017, 46, 3529-3614.

30 N. Yabuuchi, K. Kubota, M. Dahbi and S. Komaba, Chem. Rev., 2014, 114, 11636-11682.

31 S. W. Kim, D. H. Seo, X. H. Ma, G. Ceder and K. Kang, Adv. Energy Mater., 2012, 2, 710-721.

32 V. L. Chevrier and G. Ceder, J. Electrochem. Soc., 2011, 158, A1011-A1014.

33 Z. Li, J. Feng, H. Hu, Y. Dong, H. Ren, W. Wu, Z. Hu and M. Wu, J. Mater. Chem. A, 2018, 6, 18920-18927.

34 Z. Li, J. Ding and D. Mitlin, Acc. Chem. Res., 2015, 48, 16571665.
35 F. Zhang, J. Zhu, D. Zhang, U. Schwingenschlögl and H. N. Alshareef, Nano Lett., 2017, 17, 1302-1311.

36 B. Qin, H. Zhang, T. Diemant, D. Geiger, R. Raccichini, R. J. Behm, U. Kaiser, A. Varzi and S. Passerini, ACS Appl. Mater. Interfaces, 2017, 9, 26797-26804.

37 P. Y. Chang and R. A. Doong, J. Alloys Compd., 2019, 775, 214-224.

38 J. Guo, P. Li, L. Chai, Y. Su, J. Diao and X. Guo, RSC Adv., 2017, 7, 30070-30079.

39 Y. Lee, M. R. Jo, K. Song, K. M. Nam, J. T. Park and Y.-M. Kang, ACS Appl. Mater. Interfaces, 2012, 4, 3459-3464.

40 F. H. Du, Y. S. Liu, J. Long, Q. C. Zhu, K. X. Wang, X. Wei and J. S. Chen, Chem. Commun., 2014, 50, 9961-9964.

41 J. F. Wang and D. N. He, Dalton Trans., 2018, 47, 1530715311.

42 J. Liang, X. Y. Yu, H. Zhou, H. B. Wu, S. Ding and X. W. Lou, Angew. Chem., Int. Ed., 2014, 53, 12803-12807.

43 Y. Cheng, Q. Li, C. Wang, L. Sun, Z. Yi and L. Wang, Small, 2017, 13, 1701993.

44 Z. G. Wu, J. T. Li, Y. J. Zhong, J. Liu, X. D. Guo, L. Huang, B. H. Zhong and S. G. Sun, J. Alloys Compd., 2015, 620, 407-412.

45 J. F. Ye, H. J. Zhang, R. Yang, X. G. Li and L. M. Qi, Small, 2010, 6, 296-306.

46 J. Liu, J. Xiao, X. Zeng, P. Dong, J. Zhao, Y. Zhang and X. Li, J. Alloys Compd., 2017, 699, 401-407.

47 G. Gao, S. Lu, B. Dong, Y. Xiang, K. Xi and S. Ding, J. Mater. Chem. A, 2016, 4, 6264-6270.

48 C. J. Wu, Z. G. Wu, X. B. Zhang, R. Rajagopalan, B. H. Zhong, W. Xiang, M. Z. Chen, H. T. Li, T. R. Chen, E. H. Wang, Z. G. Yang and X. D. Guo, ACS Appl. Mater. Interfaces, 2017, 9, 43596-43602.

49 X. Zhao, Z. Zhang, F. Yang, Y. Fu, Y. Lai and J. Li, RSC Adv., 2015, 5, 31465-31471.

50 Y. Wang, D. Su, C. Wang and G. Wang, Electrochem. Commun., 2013, 29, 8-11.

51 Y. X. Wang, Y. G. Lim, M. S. Park, S. L. Chou, J. H. Kim, H. K. Liu, S. X. Dou and Y. J. Kim, J. Mater. Chem. A, 2014, 2, 529-534.

52 Y. C. Lu, C. Ma, J. Alvarado, T. Kidera, N. Dimov, Y. S. Meng and S. Okada, J. Power Sources, 2015, 284, 287-295. 